\title{
Imidoylation reactions at carbon
}

\author{
Alan R. Katritzky, ${ }^{*}$ Niveen M. Khashab, and Ekaterina Todadze \\ Center for Heterocyclic Compounds, University of Florida, Department of Chemistry, \\ Gainesville, Florida 32611-7200, USA \\ E-mail: katritzky@chem.ufl.edu
}

Dedicated to Prof. Irina Beletskaya on her $65^{\text {th }}$ birthday

\begin{abstract}
Methods used for imidoylation and aminoimidoylation at $\alpha$-carbon atoms of ketones, esters, nitriles, nitro compounds, sulfones and sulfoxides are summarized.
\end{abstract}

Keywords: Imidoylation, aminoimidoylation, alkoxyimidoylation, alkylthioimidoylation

\section{Contents}

1. Introduction

1.1. General

1.2. Types of C-imidoylation

2. Simple C-Imidoylation

2.1. Imidoylation of ketones

2.2. Imidoylation of esters

2.3. Imidoylation of nitriles

2.4. Imidoylation of nitro compounds

2.5. Imidoylation of sulfones

2.6. Imidoylation of sulfoxides

3. C-Aminoimidoylation

3.1. C-Aminoimidoylation of ketones

3.2. C-Aminoimidoylation of esters

3.3. C-Aminoimidoylation of sulfones

4. Conclusions

5. References 


\section{Introduction}

\subsection{General}

Imidoylations enable the preparation of a wide variety of compound classes. Thus, imidoylations at nitrogen are used for the preparation of amidines, guanidines, and $N$-substituted derivatives. ${ }^{1}$ The present review covers imidoylations at carbon, which are defined as the formation of a $\mathrm{C}-\mathrm{C}$ bond concomitant with the introduction of a $(\mathrm{C}=\mathrm{NR}) \mathrm{Y}$ group in a position previously occupied by a hydrogen (Scheme 1).

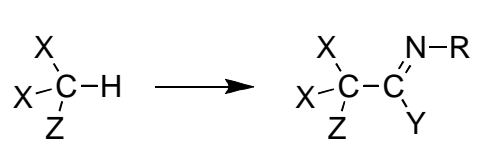

or

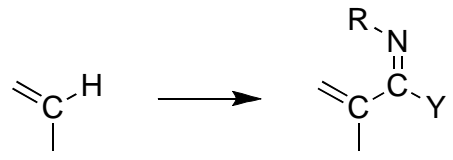

\section{Scheme 1}

\subsection{Types of $\mathbf{C}$-imidoylation}

In addition to Simple Imidoylation, i.e. the introduction of an $\mathrm{YC}(=\mathrm{NR})$-group, in which $\mathrm{Y}=\mathrm{H}$ or $\mathrm{C}$, we also consider Aminoimidoylation, in which $\mathrm{Y}=\mathrm{N}$. Thus, $\mathrm{C}$-aminoimidoylation can give amidines $\mathbf{1},{ }^{2}$ imidates $2,{ }^{2 \mathrm{a}, 3}$ amidoximes $\quad \mathbf{3}^{4}$ amidrazones $\quad \mathbf{4},{ }^{4 \mathrm{c}, \mathrm{d}}$ imidonitriles $\quad \mathbf{5}^{5}$ iminodithiocarbamates $\mathbf{6},{ }^{6}$ and imines 7 (Scheme 2). ${ }^{7}$

Imidoyl chlorides are the classical reagents for imidoylation. ${ }^{8}$ Recently, stable imidoyl benzotriazoles ${ }^{9}$ have been developed as alternatives. This review describes the different methods reported for imidoylations at carbon.

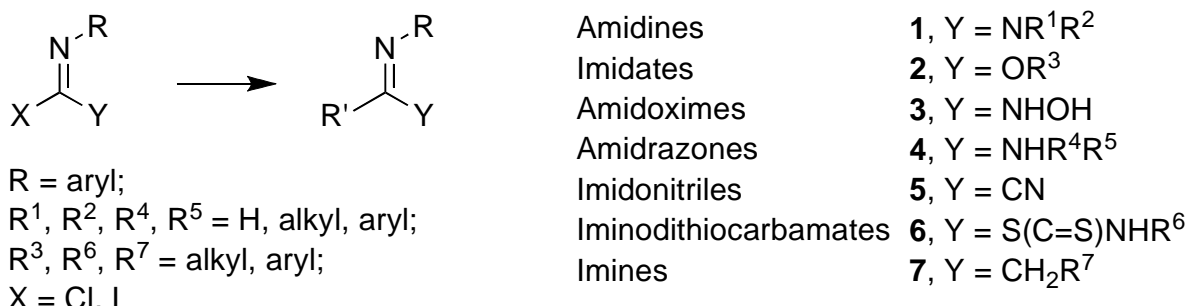

\section{Scheme 2}

\section{Simple C-Imidoylation}

\subsection{Imidoylation of ketones}

$\mathrm{C}$-Imidoylations of ketones to give $\beta$-enaminoketones 8 (Scheme 3) include (i) reactions of enolates derived from ketones $\mathbf{9}$ with imidoyl halides; this is only successful with fluorinated $\left(\mathrm{R}^{1}\right)$ imidoyl halides thus restricting its application; ${ }^{10,11}$ (ii) a single example of a palladium 
catalyzed reaction of acetonyltributyltin $\mathbf{1 0}$ with an imidoyl chloride; ${ }^{12}$ (iii) reactions of imidoylbenzotriazoles with ketones $\mathbf{1 1}$ or ketone-derived silyl enol ethers to give the desired imidoylation products $\mathbf{8}$ in $19-80 \%$ yield together with an amide as a byproduct; ${ }^{\text {a }}$ (iv) reaction of an $\mathrm{O}$-mesyloxime 12, a route that includes a $\mathrm{C}$ to $\mathrm{N}$ migration of the cis group but this is limited to symmetric oximes. ${ }^{13}(\mathrm{v})$ reactions of nitriles with methylketones 9 incorporating nitriles of aromatic $^{14 a}$ and fluorinated acids ${ }^{14 b}$ in the presence of base.
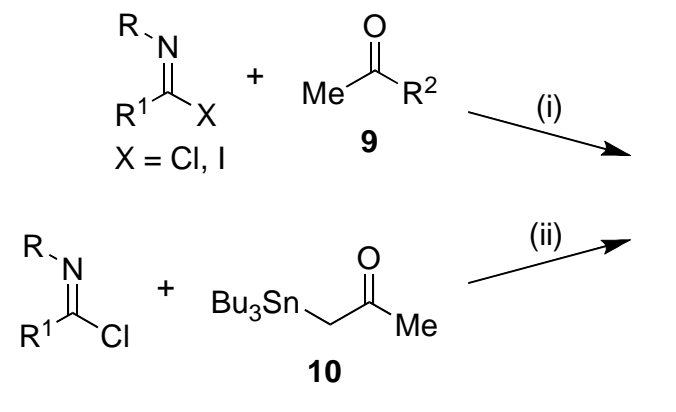<smiles>[R]NC([R])=C([R])C([R])=O</smiles><smiles>[14CH3]</smiles><smiles>[R]CC([R])=O</smiles><smiles>[R]C#[N+]C(C)=O</smiles><smiles>Nc1ccc(Nc2ccccc2)cc1</smiles>

\section{Scheme 3}

\subsection{Imidoylation of Esters}

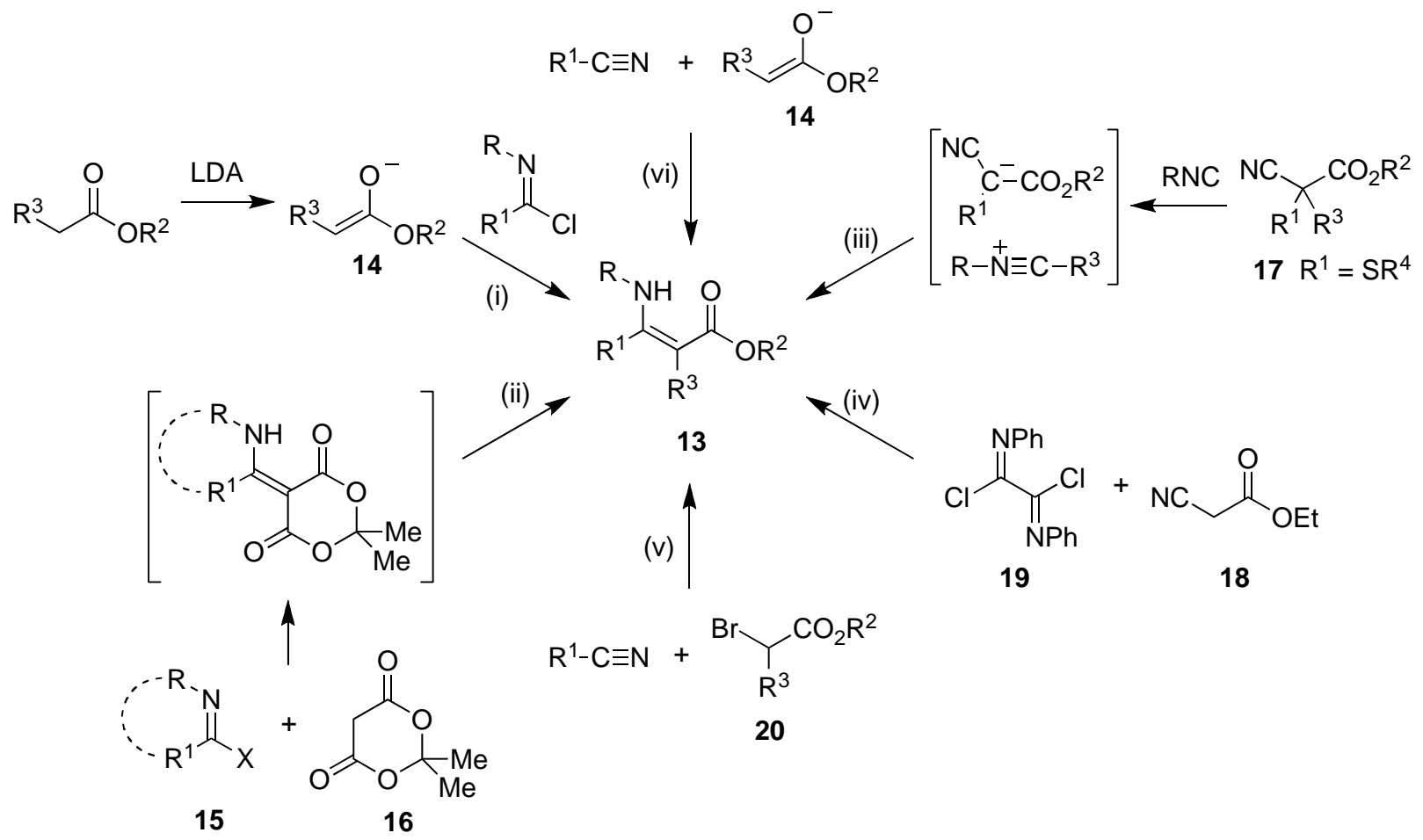

\section{Scheme 4}


C-Imidoylations of esters (Scheme 4) to give $\beta$-enamino esters 13 include (i) reactions of ester enolates 14 with fluorinated imidoyl chlorides $\left(\mathrm{R}^{1}=\text { fluorinated alkyl or aryl) }\right)^{15-17}$ (ii) reactions of malonic ester $\mathbf{1 6}$ with alkyl caboximidates, alkyl carboximidothioates, or carboximidic chlorides $15\left(\mathrm{X}=\mathrm{NHR}, \mathrm{SR}, \mathrm{Cl}\right.$, respectively); ${ }^{18}$ (iii) reactions of isocyanides with $\alpha$-alkylthio- $\alpha$-cyanoesters $17 ;^{19}$ (iv) condensation of ethyl cyanoacetate 18 with bis(imidoyl)chloride $19 ;{ }^{20}$ (v) treatment of aliphatic or aromatic nitriles with an excess of $\alpha$ bromo esters 20 in the presence of activated zinc dust, ${ }^{21}$ and (vi) reaction of nitriles with ester enolates $^{22} 14$, e.g., magnesium enolate of $t$-butyl acetate; however, the lithium enolate of $t$-butyl acetate did not give the desired product, because of the incapability of the lithium ion to take the nitrile group in its ligand sphere and the instability of the primary adduct. Method (i) is efficient for obtaining imidoylation products, but is limited to fluorinated $\left(\mathrm{R}^{1}\right)$ imidoyl chlorides. ${ }^{15-17} \mathrm{Just}$ four examples of C-imidoylation of esters have been reported using method (ii), mainly with cyclic imidoyl halides. ${ }^{18}$ Methods (iii) ${ }^{19}$ and (iv) ${ }^{20}$ are represented by unique examples for specific substrates.

Recently, we have reacted ester enolates (generated by treatment of esters with excess potassium $t$-butoxide in THF at room temperature) with imidoylbenzotriazoles 21 to give $\beta$ enamino esters 22 in $77-88 \%$ yields. ${ }^{23 a}$ (Scheme 5). There seem to be no limitations to these fast and efficient reactions.

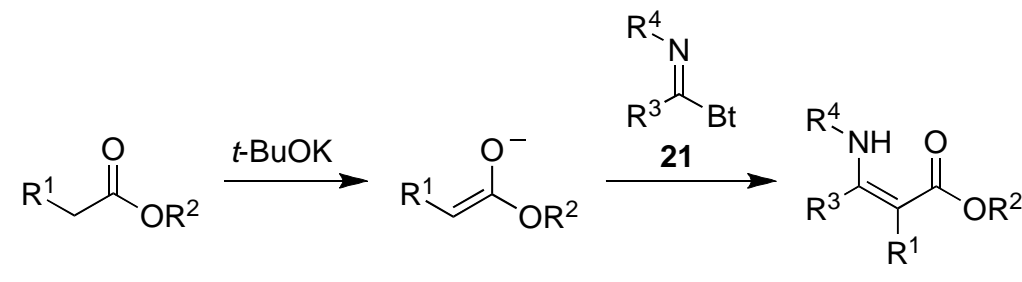

\section{Scheme 5}

\subsection{Imidoylation of nitriles}

Condensation of a nitrile anion 23a with a neutral nitrile species effects imidoylations of many nitriles 23 (Scheme 6) ${ }^{23 b, 24}$ Products $\mathbf{2 4}$ can be obtained but reactions proceed more rapidly with $\mathrm{R}^{1}=\mathrm{Ar}$ in the neutral nitrile $\mathbf{2 3 b}$, because reactions between two different aliphatic nitriles lead to the formation of side products. ${ }^{23 b}$

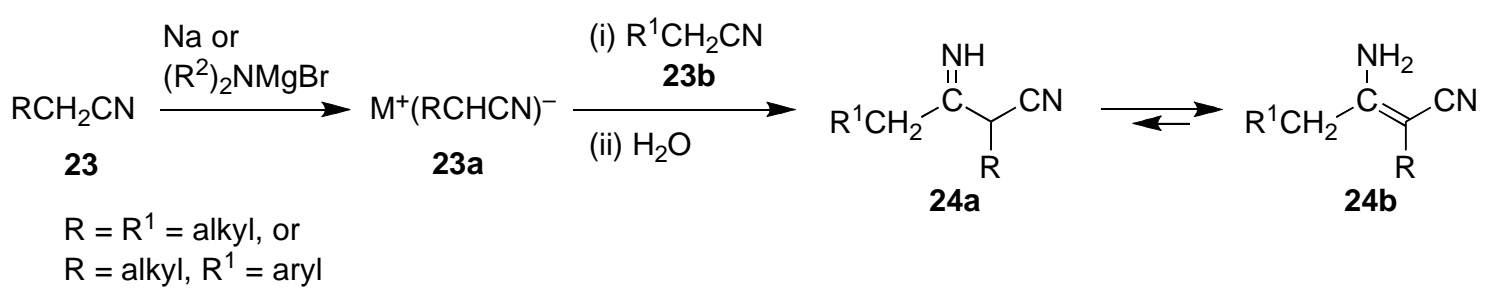

\section{Scheme 6}




\subsection{Imidoylation of nitro compounds}

A single C-imidoylation of a nitro compound has been reported. ${ }^{25}$ The reaction of ethyl nitroacetate 26 with imidoyl chloride 25 gives the enamine $27 \mathbf{b}$ (Scheme 7).

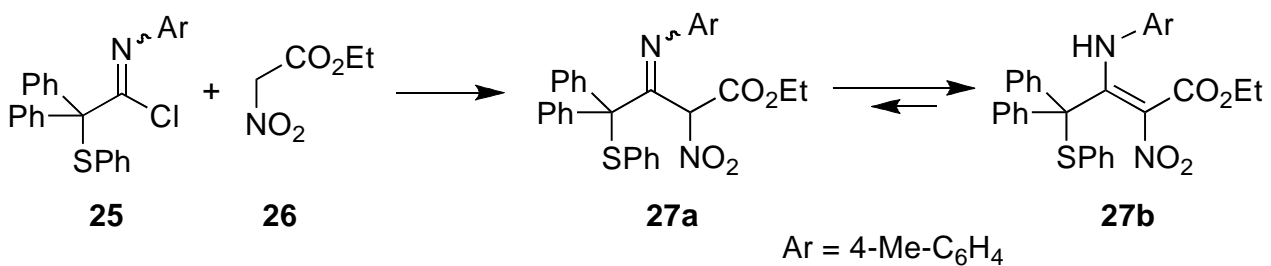

\section{Scheme 7}

A general C-imidoylation of nitro compounds was recently established in our group. ${ }^{23 a} \beta$ Nitroenamines 28 (3 examples) were prepared in 34-60\% yield from the reaction of imidoylbenzotriazoles 21 with nitroethane (Scheme 8). Yields were improved by using DMSO as a solvent rather than THF.

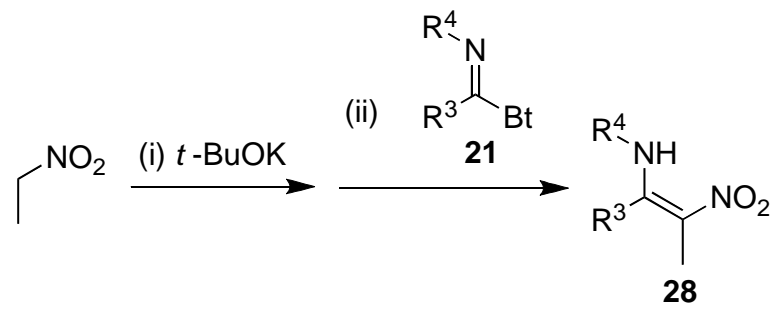

\section{Scheme 8}

\subsection{Imidoylation of sulfones}

Preparation of $\beta$-iminosulfones 29 involves (i) reactions of fluorinated imidoyl chlorides $(\mathrm{R}=$ fluorinated alkyl or aryl) and arylmethyl sulfones ${ }^{26}$ in $68-94 \%$ yields and (ii) reactions of alkyland aryl-sulphonyl carbanions with nitriles ${ }^{27}$ prepared by Corey's method ${ }^{28}$ (Scheme 9). In both cases products were isolated as a mixture of imino and enamino tautomers 29a and 29b, respectively.

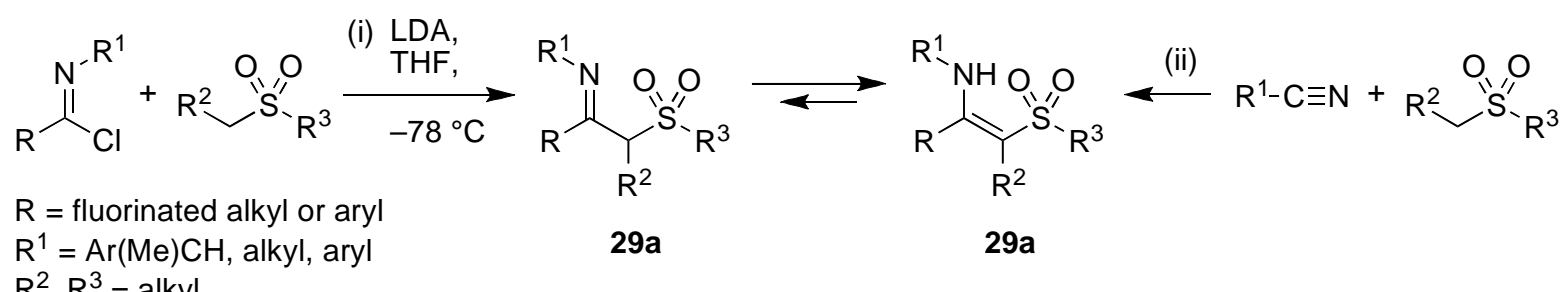

\section{Scheme 9}


Three C-imidoylations of sulfones by imidoylbenzotriazoles $\mathbf{2 1}$ to form $\beta$-iminosulfones $\mathbf{2 9}$ (53-97\%) have been found recently, ${ }^{23 a}$ but no examples were reported with aliphatic substituents in place of $N$-phenyl, which could be a limitation.

\subsection{Imidoylation of sulfoxides}

Imidoylations of sulfoxides to give $\beta$-iminosulfoxides 31 (Scheme 10) involve the reaction of sulfinylmethyl carbanion derived from methylsulfoxides $\mathbf{3 0}$ with (i) fluorinated imidoyl chlorides $\left(\mathrm{R}=\mathrm{CF}_{3}, \mathrm{CF}_{2} \mathrm{Cl}, \mathrm{CF}_{2} \mathrm{CF}_{3}, \mathrm{CF}_{2} \mathrm{H}, \mathrm{CFH}_{2}\right)^{29,30}$ or (ii) nitriles. ${ }^{31}$ Fluorinated imidoyl chlorides react well with sulfinylmethyl carbanions regardless of the substituents in the imidoyl chlorides $(\mathrm{R}=$ $\mathrm{R}_{\mathrm{F}}, \mathrm{R}^{1}=$ aryl or alkyl) and in the sulfoxide 30, and require an excess of LDA. The reaction does not affect the configuration of the sulfur atom, and gives $\beta$-iminosulfoxides with optical purities comparable to those of the starting sulfoxide. ${ }^{29 a} \beta$-Iminosulfoxides can also easily be converted into the corresponding sulfinyl ketones by treatment with mineral acid. However, these methods do not provide a general route to $\mathrm{C}$-imidoylation of sulfoxides because method (i) is limited mainly to fluorinated imidoyl chlorides, and the yields of method (ii) are greatly influenced by the nature of the methylsulfinyl carbanion $\left(\mathrm{R}^{2}=\right.$ alkyl, aryl $)$ for reasons which are not explained by the authors.

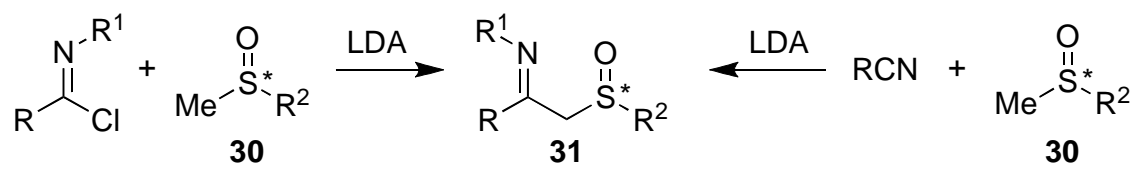

\section{Scheme 10}

Recently, we have reported the reaction of sulfoxides with potassium $t$-butoxide followed by imidoylbenzotriazole 21 to give $\beta$-iminosulfoxides 32 in $48-78 \%$ yields (Scheme 11 ). ${ }^{23 a}$ The reaction required $2 \mathrm{~h}$ at $20{ }^{\circ} \mathrm{C}$ to reach completion and worked well with both alkyl and aryl substituents $\left(\mathrm{R}^{1}, \mathrm{R}^{2}=\right.$ alkyl, aryl $)$.

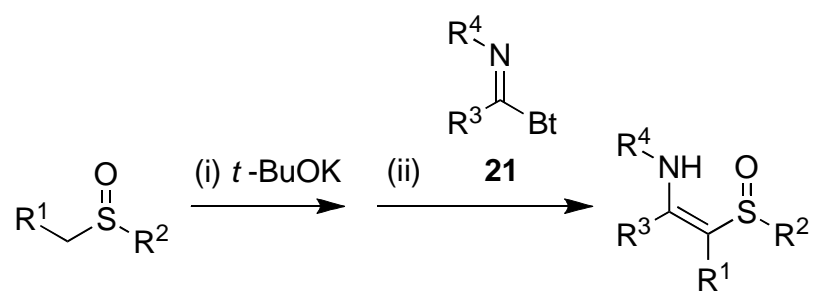

32

\section{Scheme 11}




\section{C-Aminoimidoylation}

\subsection{C-Aminoimidoylation of ketones}

Oxoketene aminals 33, which are formally C-aminoimidoylation products of ketones, have been prepared from (i) activated methylene compounds and isothiocyanates followed by the reaction with amines, ${ }^{32}$ (ii) oxoketene N,S-acetals and lithio derivatives of secondary amines or aniline ${ }^{33}$ or (iii) tris(dimethylamino)ethoxymethane and simple ketones. ${ }^{34}$ Methods (i) - (iii) (Scheme 12) are multistep syntheses with overall yields averaging $30 \%$.

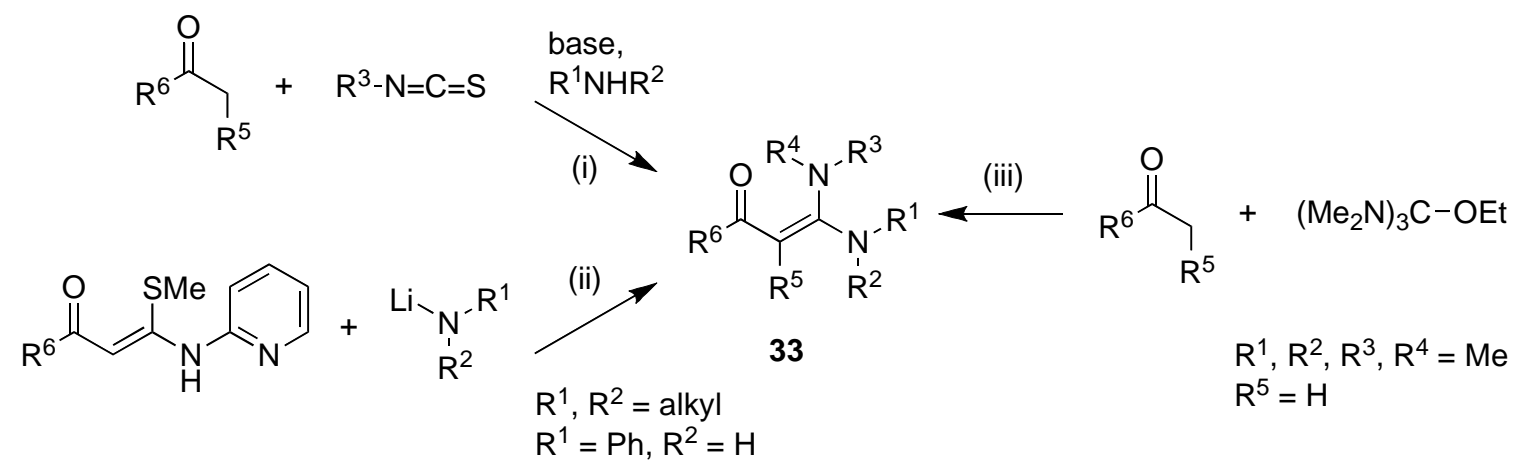

\section{Scheme 12}

The benzotriazole methodology allows the one step preparation of ketene aminals 35 in $27-$ $32 \%$ yields: ${ }^{35} \mathrm{C}$-aminoimidoylations of ketones have been achieved at $20{ }^{\circ} \mathrm{C}$ using benzotriazole-1-carboxamidines 34 (Scheme 13); the reactions occurred with both aromatic and aliphatic substituents.

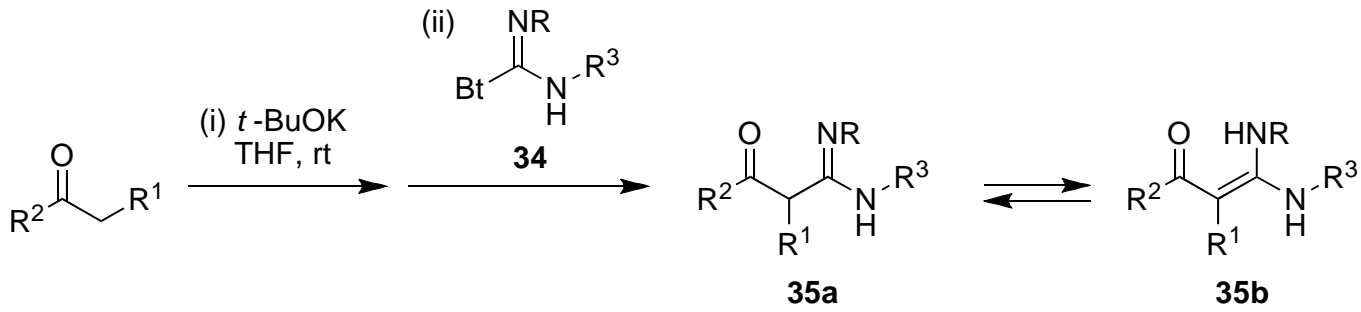

\section{Scheme 13}

\subsection{C-Aminoimidoylation of esters}

While no literature $\mathrm{C}$-aminoimidoylation of esters was found, $\mathrm{C}$-aminoimidoylated esters 37 were obtained by ring opening of isoxazolones 36 with amines (Scheme 14). ${ }^{36}$ Recently, Caminoimidoylation of esters from the reaction of their enolates with benzotriazole-1- 
carboxamidines 34 was achieved at $20{ }^{\circ} \mathrm{C}$ to produce 37 in $20-63 \%$ yields (Scheme 14 ). ${ }^{35}$ The predominant tautomeric structures of amidines 37 (Scheme 14) were determined by 2D NMR.

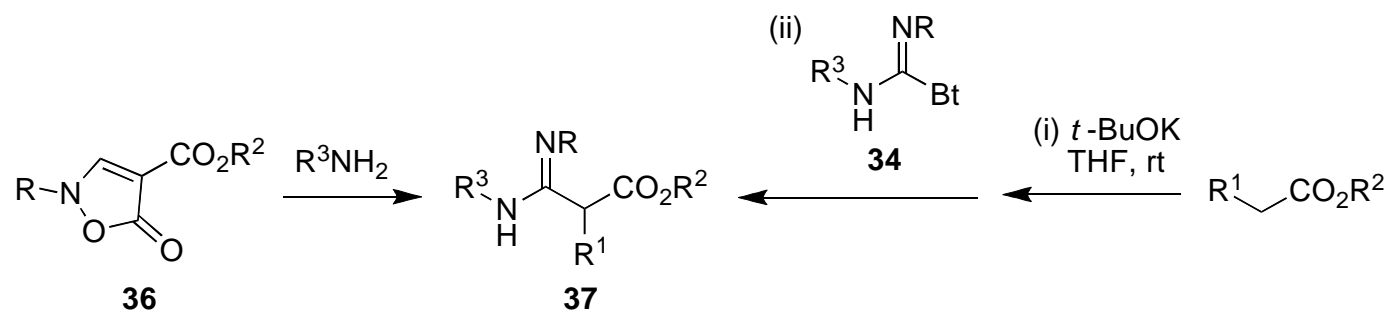

\section{Scheme 14}

\subsection{C-Aminoimidoylation of sulfones}

Likewise, no literature example of $\mathrm{C}-\mathrm{C}$ bond formation to provide a $\mathrm{C}$-aminoimidoylation product of sulfones was found; one potential imidoylation product $\mathbf{3 8}$ has been prepared from $\beta, \beta$-dichlorovinyl propyl sulfone by reaction with 4-methoxyaniline (Scheme 15). ${ }^{37}$

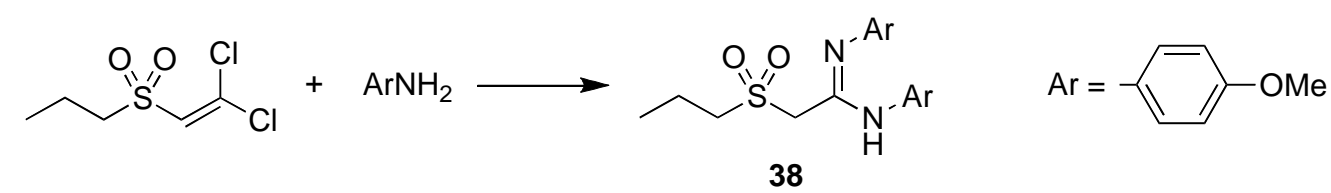

\section{Scheme 15}

Benzotriazole-1-carboxamidine 34 effectively C-aminoimidoylate sulfone 39 (upon deprotonation by excess potassium $t$-butoxide in THF) at $20{ }^{\circ} \mathrm{C}$ to give 40 in $30 \%$ yield (Scheme 16). ${ }^{35}$ However, application of this method is limited; It was only successful with alkyl phenyl sulfone 39.

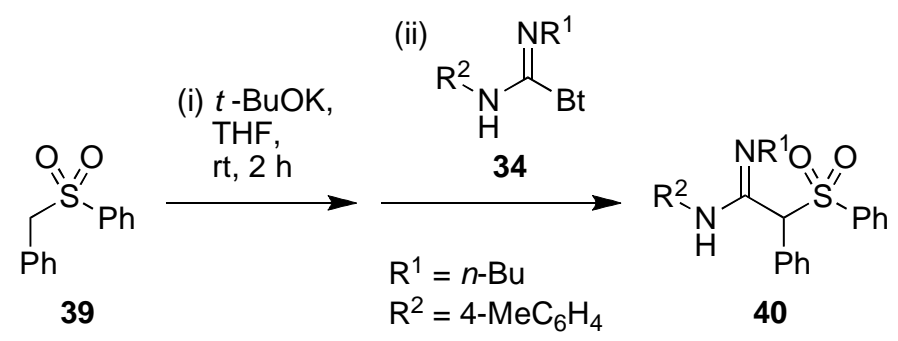

\section{Scheme 16}




\section{Conclusions}

A short review of imidoylation reactions at carbon is presented and the most significant literature reactions considered and summarized.

\section{References}

1. Katritzky, A. R.; Rogovoy, B. Arkivoc 2005, iv, 49.

2. (a) Paul, H; Weise, A.; Dettmer, R. Ber. Dtsch. Chem. Ges. 1965, 98, 1450. (b) Kotali, A.; Lafazanis, I. S. Arkivoc 2003, vi, 91.

3. (a) Schulenberg, J. W.; Archer, S. J. Am. Chem. Soc. 1960, 82, 2035. (b) Rowe, J. E. Synthesis 1980, 2, 114.

4. (a) Ley, H. Ber. Dtsch. Chem. Ges. 1898, 31, 240. (b) Ley, H. Ber. Dtsch. Chem. Ges. 1901, 34, 2620. (c) Houghton, P. G.; Pipe, D. F.; Rees, C. W. J. Chem. Soc., Perkin Trans. I 1985, 1471. (d) Romine, J. L.; Martin S. W.; Gribkoff V. K.; Boissard, C. G.; Dworetzky, S. I.; Natale, J.; Li, Y.; Gao, Q.; Meanwell, N. A.; Starrett, J. E., Jr. J. Med. Chem. 2002, 45, 2942.

5. (a) Clark, N. G., Cawkill, E. Tetrahedron Lett. 1975, 31, 2717. (b) Smith, J. G.; Irwin, D. C. Synthesis 1978, 12, 894.

6. (a) Leo, H. Chem. Ber. 1877, 10, 2133. (b) Barnikow, G.; Lehner, J. Z. Chem. 1990, $30,89$.

7. Quast, H.; Frank, R.; Heublein, A.; Schmitt, E. Liebigs Ann. Chem. 1979, 1, 83.

8. Patai, S. In The Chemistry of Functional Groups; Interscience Publishers: New York, 1970; p 597.

9. (a) Katritzky, A. K.; Hayden, A. E.; Kirichenko, K.; Pelphery, P.; Ji, Y. J. Org. Chem. 2004, 69, 5108. (b) Katritzky, A. R.; Huang, T.; Voronkov, M. V. J. Org. Chem. 2001, 66, 1043.

(c) Katritzky, A. R.; Fang, Y.; Donkor, A.; Xu, J. Synthesis 2000, 14, 2029. (d) Katritzky, A. R.; Cai, C.; Singh, S. K. J. Org. Chem. 2006, 71, 3375. (e) Katritzky, A. R.; Khashab, N. M.; Kirichenko, N.; Singh, A. J. Org. Chem. 2006, 71, 9051.

10. Fustero, S.; García de la Torre, M.; Pina, B.; Fuentes, A. S. J. Org. Chem. 1999, 64, 5551.

11. Yu, H.; Huang, W. J. Fluorine Chem. 1997, 84, 65.

12. Kosugi, M.; Koshiba, M.; Atoh, A.; Sano, H.; Migita, T. Bull. Chem. Soc. Jpn. 1986, 59, 677.

13. Matsumura, Y.; Fujiwara, J.; Maruoka, K.; Yamamoto, H. J. Am. Chem. Soc. 1983, 105, 6312.

14. (a) Sosnovskikh, V. Ya.; Kostrikova, T. P. Zh. Org. Khim. 1986, 22, 883. (b) Lee, L. F.; Sing, Y. L. J. Org. Chem. 1990, 55, 380.

15. Fustero, S; Pina, B.; Simón-Fuentes, A. Tetrahedron Lett. 1997, 38, 6771.

16. Fustero, S.; Pina, B.; García de la Torre, M.; Navarro, A.; Ramírez de Arellano, C.; Simón, A. Org. Lett. 1999, 1, 977. 
17. Fustero, S.; Pina, B.; Salavert, E.; Navarro, A.; Ramírez de Arellano, M. C.; Fuentes, A. S. J. Org. Chem. 2002, 67, 4667.

18. Célérier, J. P.; Richaud, M. G.; Lhommet, G. Synthesis 1983, 3, 195.

19. Morel, G.; Marchand, E.; Foucaud, A. J. Org. Chem. 1985, 50, 771.

20. Langer, P.; Wuckelt, J.; Döring, M. J. Org. Chem. 2000, 65, 729.

21. (a) Hannick, S. M.; Kishi, Y. J. Org. Chem. 1983, 48, 3833. (b) Lee, A. S.-Y.; Cheng, R.-Y. Tetrahedron Lett. 1997, 38, 443.

22. Hiyama, T.; Kobayashi, K. Tetrahedron Lett. 1982, 23, 1597.

23. (a) Katritzky, A. R.; Khashab, N. M. Singh, A. Arkivoc 2007, v, 263. (b) Lorz, E.; Baltzly, R. J. Am. Chem. Soc. 1948, 13, 1904.

24. Reynolds, G. A.; Humphlett, W. J.; Swamer, F. W.; Hauser, C. R. J. Org. Chem. 1951, 16, 165.

25. Mironova, D. F.; Loginova, N. A. Ukr. Khim. Zh. 1983, 49, 65. Chem. Abstr. 1983, 106., 137998.

26. Fustero, S.; Soler, J. G.; Bartolomé, A.; Roselló, M. S. Org. Lett. 2003, 5, 2707.

27. Muraoka M. J. Chem. Soc., Perkin Trans. I 1978, 9, 1345.

28. Corey, E. J.; Chaykovsky, M. J. Am. Chem. Soc. 1965, 87, 1345.

29. (a) Fustero, S.; Navarro, A.; Asensio, A. Tetrahedron Lett. 1997, 38, 4891. (b) Fustero, S.; Navarro, A. Pina, B.; Asensio, A. J. Org. Chem. 1998, 63, 6210.

30. Acherki, H.; Alvarez-Ibarra, C.; de-Dios, A.; Quiroga, M. L. Tetrahedron 2002, 58, 3217.

31. Yokoyama, M.; Takeshima, T. Tetrahedron Lett. 1978, 2, 147.

32. Shi, Y.; Zhang, J.; Grazier, N.; Stein, P. D.; Atwal, K. S.; Traeger, S. C.; Callahan, S. P.; Malley, M. F.; Galella, M. A.; Gougoutas, J. Z. J. Org. Chem. 2004, 69, 188.

33. Barun, O.; Ila, H.; Junjappa, H. J. Org. Chem. 2000, 65, 1583.

34. Kantlehner, W.; Mergen, W. W. Synthesis 1979, 5, 343.

35. Katritzky, A. R.; Khashab, N. M.; Haase, D. N.; Yoshioka, M.; Ghiviriga, I.; Steel, P. J. J. Org. Chem. 2007, 72, 6742.

36. Wicks, Z. W. Jr.; Patel, P. P. J. Org. Chem. 1981, 46, 4068.

37. Martynov, A. V.; Mirskova, A. N.; Kalikhman, I. D.; Makerov, P. V.; Vitkovskii, V. Y.; Voronkov, M. G. Zh. Org. Khim. 1979, 15, 2349. Chem. Abstr. 1979, 92, 215006. 